\title{
Fenomenología de la percepción y nuevo realismo. Merleau-Ponty, Meillassoux y Markus Gabriel
}

\section{[Phenomenology of Perception and New Realism. Merleau-Ponty, Meillassoux and Markus Gabriel]}

\author{
MARIO TEODORO RAMÍREZ \\ Instituto de Investigaciones Filosóficas Luis Villoro \\ Universidad Michoacana de San Nicolás de Hidalgo \\ marioteo56@yahoo.com.mx \\ mario.ramirez@umich.mx
}

\begin{abstract}
Resumen: Este artículo plantea la tesis de que la filosofía fenomenológica de la percepción de Merleau-Ponty, en la medida en que es crítica tanto del empirismo como del idealismo, apunta hacia una forma de realismo (realismo perceptual). Para argumentar en favor de esta idea y mostrar la vigencia del pensador francés, se contrastan los planteamientos de éste con posturas del "realismo especulativo" de Meillassoux, del "nuevo realismo" de Gabriel y del "realismo plural" de Taylor y Dreyfus. Se propone el concepto de "realismo ontológico" para apuntalar la postura de Merleau-Ponty y a los planteamientos de este ensayo.
\end{abstract}

Palabras clave: correlacionismo; cuerpo; percepción; campo fenoménico; realismo

\begin{abstract}
This essay claims that the thesis of Merleau-Ponty's phenomenology of perception, insofar that it criticizes both empirism and idealism, points towards a form of realism (perceptual realism). To argue this, and to show the validity of the work of the French thinker, I contrast his thoughts with the approaches of "speculative realism" of Meillassoux, of the "new realism" of Gabriel and of "plural realism" of Taylor and Dreyfus. I propose the concept of "ontological realism" in order to support the posture of Merleau-Ponty and the arguments of this essay.
\end{abstract}

Key words: correlationism; body; perception; phenomenic field; realism

En el contexto de la discusión actual sobre el realismo deseo defender la tesis de que la filosofía fenomenológica de la percepción de Maurice Merleau-Ponty, en la medida en que es crítica tanto del empirismo como del idealismo, apunta hacia una forma de realismo (realismo perceptual) que, para precisar su diferencia con el empirismo y el realismo científico, propongo denominar "realismo ontológico". Para arribar a esta propuesta contrastaré algunos planteamientos del filósofo francés con los de ciertos autores vinculados con el llamado "nuevo realismo". Así, 1) defenderé la postura de Merleau-Ponty ante la crítica de Quentin Meillassoux según la cual la fenomenología es una filosofía 
correlacionista y subjetualista; 2) evaluaré si la caracterización crítica de Markus Gabriel del modelo fenomenológico de la percepción es adecuada para definir la concepción del filósofo francés; 3) con base en planteamientos de Richard Dreyfus, Charles Taylor y Samuel Todes, explicaré en forma general el significado y el valor del realismo perceptual del filósofo francés, y 4) abundaré en la conclusión en las consecuencias de interpretar a Merleau-Ponty como un realista con la propuesta del concepto de realismo ontológico como una forma de congeniar el realismo perceptual del filósofo francés con el realismo científico y las posturas del nuevo realismo.

Aunque el "nuevo realismo" que ha invadido la filosofía congrega a muchos autores y a diversas perspectivas, supondré aquí que todas éstas comparten el rechazo hacia las posturas subjetivistas, idealistas y humanistas del pensamiento de los siglos XIX y XX y el cuestionamiento de la prioridad de la epistemología sobre la ontología. Si bien hay diferencias importantes entre los autores del nuevo realismo que tendré en cuenta, señalaré esas diferencias sólo cuando sean pertinentes para precisar las aportaciones de Merleau-Ponty para la comprensión del realismo. Cabe señalar que, a diferencia de otros enfoques de la discusión entre la fenomenología y el nuevo realismo, no presupongo la validez indiscutible de ninguna de estas posturas aun si suponemos que son indudablemente opuestas. Más bien me propongo explorar sus posibles convergencias o la manera como ciertos límites del pensamiento fenomenológico empujan hacia un encuentro con el nuevo realismo. Como dice Tom Sparrow: "si la fenomenología nos hizo escuchar las cosas mismas, el realismo especulativo nos las entrega realmente". ${ }^{1}$

\section{1. ¿Es Merleau-Ponty un correlacionista? Tres filósofos entran a un bar...}

En este apartado trataré de responder a la pregunta de si MerleauPonty es un filósofo "correlacionista" y "subjetualista", conceptos acuñados por Quentin Meillassoux, ${ }^{2}$ quien defiende una filosofía especula-

1 "If phenomenology harkened us to the things themselves, speculative realism actually delivers them" (Sparrow 2014, p. xi).

${ }^{2}$ La primera formulación de la propuesta filosófica de Meillassoux se encuentra en su tesis de doctorado Linexistence divine de 1997 (inédita, accesible por internet). En 2006 publicó Après la finitude. Essai sur la nécesité de la contingence, ya traducida al español (Meillassoux 2015). En torno a las novedosas tesis de esta obra se llevó a cabo en 2007 un coloquio en Londres en el que participaron Graham Harman, Ray Brassier y Iain Hamilton Grant. Este evento dio origen al llamado 
tiva ("materialismo especulativo") como alternativa tanto a la filosofía analítica como a la filosofía fenomenológica. ${ }^{3}$ Cabe aclarar que, hasta donde sé, Meillassoux no se refiere en forma directa a Merleau-Ponty, pero sí a la fenomenología en general —empezando por Husserl-.

Según la ahora famosa formulación de Meillassoux, toda la filosofía moderna en sus distintas y a veces disímbolas posturas, incluido el posmodernismo, se rige con el paradigma correlacionista, es decir, con la suposición de que el tema y referente de la reflexión filosófica es la correlación sujeto-objeto -o conciencia-mundo, lenguaje-realidad, existente-Ser, etc.- - y que no hay algo más allá de esta correlación, y si lo hubiera sería racionalmente inaccesible. Entre otras definiciones de "correlacionismo", en Meillassoux podemos encontrar la siguiente:

Por correlacionismo entiendo en una primera aproximación, toda filosofía que sostiene la imposibilidad de acceder por medio del pensamiento a un ser independiente del pensamiento. No tenemos nunca acceso, según este tipo de filosofía, a un objeto (entendido en un sentido general) que no esté ya correlacionado a un acto de pensamiento. (Meillassoux 2016, p. 73)

El paradigma de la correlación, tal como lo estableció Kant, imposibilita cualquier metafísica u ontología, es decir, cualquier filosofía del Ser en cuanto tal, de lo real en sí mismo. Sólo podemos hablar del fenómeno, de lo que "se nos aparece"; es decir, de aquello que se presenta a la conciencia o a la realidad humana en general o bien, a la manera de la filosofía analítica, de lo que cae en el marco de una teoría, de una metodología o en un lenguaje.

Según Meillassoux, la fenomenología es un modelo de filosofía correlacionista (Meillassoux 2015, p. 30): la correlación noesis-noema (acto de pensar-objeto del pensamiento) de Husserl 1949 (pp. 210 y ss.) o la correlación Dasein-Mundo o la "copertenencia (Zusammengehörig-

"realismo especulativo". Por otra parte, el filósofo alemán Markus Gabriel y el filósofo italiano Maurizio Ferraris inauguraron lo que llamaron el "nuevo realismo" en 2011 (Ferraris 2013, p. 35). Véase Ramírez 2016.

3 "La conciencia y el lenguaje fueron los dos 'medios' principales de la correlación en el siglo Xx, dando sostén respectivamente a la fenomenología y a las diversas corrientes de la filosofía analítica" (Meillassoux 2015, p. 30). Ahí mismo (p. 73) menciona a Wittgenstein y a Heidegger como representantes de lo que llama el "correlacionismo fuerte" (la correlación sujeto-objeto es lo único que hay), que radicaliza el correlacionismo débil de Kant (la correlación no lo es todo, pues existe lo nouménico). 
keit) originaria del hombre y el ser" que Heidegger denomina Ereignis 4 o, podría agregarse, la correlación cuerpo-mundo (vidente-visible) de Merleau-Ponty. ${ }^{5}$ Para el realismo especulativo la única ontología válida y necesaria para superar el idealismo, subjetivismo y antropocentrismo de la filosofía moderna es la que no se funda en ningún tipo de experiencia, sino que es el resultado, a la manera cartesiana, de un ejercicio del pensamiento puro - especulativo — o de la razón pura. Según Meillassoux, sólo una ontología especulativa nos permite afirmar que existe una realidad absoluta, independiente de nosotros y, de esta manera, superar el escepticismo, relativismo y nihilismo del pensamiento moderno $\mathrm{y}$, en particular, del posmoderno.

Ahora bien, ¿es verdad que la filosofía de Merleau-Ponty cae, sin más, en el correlacionismo? Así parece sugerirlo el increíble y curioso encuentro en un bar parisino en 1951 entre el filósofo analítico británico A.J. Ayer y los franceses Georges Bataille y Merleau-Ponty. “'Un pornógrafo, un fenomenólogo y un positivista lógico entraron a un bar'. Esto parece el inicio de un chiste" (Vrahimis 2013, p. 87). O de una broma surrealista; pero es cierto. Según Vrahimis, en esa reunión la disputa giró en torno a si el sol existía antes de que nosotros existiéramos, un argumento parecido al que ahora usa Meillassoux con los términos "ancestralidad" y "archifósil". 6 A Ayer le parecía una afirmación incontrovertible — por científica-, mientras que Bataille y Merleau-Ponty, que compartían la perspectiva fenomenológica, sostenían que el sol "antes de nosotros" sólo existe "para nosotros" y no "en sí mismo".

Ted Toadvine, estudioso de la filosofía de Merleau-Ponty, también menciona aquel singular encuentro y se ocupa de defender -explicándola, matizándola - la posición del fenomenólogo francés, no sólo frente a Ayer, sino también frente al señalamiento de Meillassoux. En

4 "La noción de Ereignis, central en el último Heidegger, sigue siendo entonces fiel a la exigencia correlacional heredada de Kant, y prologada por la fenomenología husserliana" (Meillassoux 2015, p. 33). Heidegger define el Ereignis de la siguiente forma: "Evento: la segura luz del esenciarse del ser [Seyn] en el extremo horizonte de la más íntima indigencia del hombre histórico" (Heidegger 2003, p. 42).

${ }^{5}$ Sobre la crítica neorrealista a la fenomenología, véase Sparrow 2014. Véase también la respuesta a este texto desde la postura de la fenomenología en Zahavi 2016. Sobre la discusión entre fenomenología y realismo especulativo, véase PhænEx. Revue de théorie et culture existentialistes et phénoménologiques, vol. 12, no. 2, 2018, número especial sobre realismo especulativo, en particular el artículo de Robert Booth.

${ }^{6}$ Esto es, según Meillassoux, lo que existió antes de la vida humana y de la vida en general y que de ninguna manera puede ser "correlato" de la conciencia. Cfr. Meillassoux 2015, pp. 23-53. 
un pasaje del capítulo sobre la temporalidad de la Fenomenología de la percepción, Merleau-Ponty expone su idea sobre la preeminencia del mundo vivido (el Lebenswelt) sobre el mundo objetivo de la visión científica. Dice nuestro filósofo:

¿Qué quiere decirse exactamente al afirmar que el mundo existía antes de las consciencias humanas? Se quiere decir, por ejemplo, que la Tierra salió de una nebulosa primitiva en la que las condiciones de vida no estaban aún reunidas. Ahora bien, cada uno de estos vocablos, lo mismo que cada una de las ecuaciones de la física, presupone nuestra experiencia precientífica del mundo, y esta referencia al mundo vivido contribuye a construir su significación válida. Nada me hará comprender jamás lo que podría ser una nebulosa no vista por nadie. La nebulosa de Laplace no está tras de nosotros, en nuestro origen, está ante nosotros, en el mundo cultural. (Merleau-Ponty 1993, p. 440)

Sin embargo, ¿no es esto una profesión de fe subjetivista, el mejor ejemplo de lo que Meillassoux cuestiona del correlacionismo? El propio Merleau-Ponty - tan antirrealista como antiidealista que era- evita esa interpretación. Dice enseguida: "Y, por otra parte, ¿̇qué quiere decirse cuando se afirma que no hay mundo sin un ser-del-mundo? No que el mundo sea constituido por la consciencia, sino, al contrario, que la consciencia ya se halla siempre en acción en el mundo" (p. 440). La reconocida "ambigüedad" de la filosofía de Merleau-Ponty (Waelhens 1978) le permite presentar argumentos en ambos frentes, el realista y el idealista, pues su tema no es la conciencia ni tampoco el ser, sino el cuerpo, ese extraño ser que es sustento de la subjetividad y del pensamiento y que a la vez se encuentra íntimamente entramado con todo lo existente.

Respecto al tema de la temporalidad, el pasado, la ancestralidad, Toadvine recuerda los planteamientos de Merleau-Ponty acerca de un "pasado puro" o un "tiempo mítico". " "El pasado elemental", le llama Toadvine, que es antes que todo: una anterioridad absoluta que precede a todo acto de conciencia $-\mathrm{y}$ a todo ser viviente y a todo algo en el mundo- y que, sin embargo, no es ajeno a nuestra experiencia vivida, sino, más bien, sólo se aprehende en su lejanía "inaprehensible", desde ella, o, mejor, desde nuestra corporalidad material, desde una naturaleza en la que participamos y que carga consigo en sus distintos estratos todo el pasado — bioquímico, geológico, cósmico- del universo. Como alguien dijo: estamos hechos del mismo material que las

${ }^{7}$ Toadvine 2014, p. 266. Véase Merleau-Ponty 1970, p. 293. 
estrellas. En respuesta a la crítica, Toadvine señala a Meillassoux que no podríamos entender el pasado ancestral si no es por la experiencia de un "pasado en general" que tiene una subjetividad corporal que se entronca con un universo más viejo que todo: "la corporalidad proustiana como guardiana del pasado", como dice Merleau-Ponty 1970 (p. 293). El pasado ancestral de que habla Meillassoux no es algo que sólo la ciencia o el pensamiento especulativo estarían preparados para captar: nuestro propio cuerpo es un cuerpo ancestral, un archifósil viviente. "En la sensibilidad, no sólo recreo mi propia animalidad, sino que también, a través de mi participación en la elementalidad de las cosas, tomo en el corazón de mi existencia toda la historia del universo". (Toadvine 2014, p. 276). Ahora bien: esta experiencia —cuasi inconsciente o semiconsciente- de la ancestralidad de mi propio cuerpo es lo que me permite poder comprender lo que significa el "objeto ancestral" de Meillassoux, lo que permite que tal objeto tenga sentido para nosotros y llegue a ser pensable.

"Co-participación", "co-existencia", "comunidad", "superposición", "promiscuidad", "entrelazo", "quiasmo" son los términos que usa Merleau-Ponty (Ramírez 2013) a lo largo de su trabajo filosófico; se parecen a "correlación" pero con una leve diferencia, pues la correlación presupone una dualidad dicotómica, es decir, que hay de principio dos entes o realidades de naturaleza distinta y hasta contrapuesta: el sujeto y el objeto, la conciencia y la realidad, el lenguaje y el mundo. ${ }^{8}$ MerleauPonty nunca adopta tal perspectiva; es un pensador de la diferencia sin ser un pensador de la dicotomía, de la oposición. Por esta razón, no puede ser correlacionista. Para que haya una correlación se requiere que haya dos, y para Merleau-Ponty no hay dos, ni uno, ni muchos en el sentido simplemente cuantitativo. Lo que hay, como dice en Lo visible y lo invisible, es una generalidad (Merleau-Ponty 1970, p. 174), un ser difuso, "pre-ser" o "híper-ser" (ser onírico) que lo incluye todo. Llama la atención que en uno de sus últimos escritos Merleau-Ponty cuestiona el "correlacionismo" husserliano: ni el cuerpo, ni el tiempo interior, ni el otro, ni la historia, dice, "se dejan conducir bajo la correlación de la consciencia y de sus objetos, de la nóesis y del nóema" (Merleau-Ponty 1972, p. 10). ${ }^{9}$ Sin embargo, la crítica que hace al correlacionismo no se dirige contra la afirmación de una realidad absoluta, sino contra otra

${ }^{8}$ Como señala Robert Booth: "On my account, any serious version of the correlationist charge is misdirected because Merleau-Pontians deny the ontological primacy of the poles between which correlational 'access' is said to occur" (Booth 2018, p. 37).

${ }^{9}$ Ahí mismo aparecen las expresiones "pre-ser" y "ser onírico". 
manera de concebir las relaciones como tales. Entre el sujeto sensible y el ser sensible hay comunidad: "la sensación es, literalmente, una comunión" (Merleau-Ponty 1993, p. 228); y, con una metáfora cristiana, explica: igual que "el sacramento no sólo simboliza bajo unas especies sensibles una operación de la Gracia, sino que es además la presencia real de Dios" (p. 227), también en el ser sensible hay una especie de transustanciación entre el sujeto viviente y el mundo vivido; una unidad que no cancela la diferencia. Sé que existe un Ser independientemente de mi conciencia por la simple razón de que mi propia vida corporal, que es parte del Ser, trasciende de forma continua mi propia conciencia. No hay un correlacionismo entre el sujeto corporal y el mundo porque el sujeto es parte del mundo, está hundido en el mundo y percibe, actúa y piensa como desde el corazón de la existencia. ${ }^{10}$

Ahora bien, si no cabe definir a Merleau-Ponty como un correlacionista, dado que no es dualista (y el correlacionismo presupone el dualismo), ¿es entonces un monista, es decir, un pensador de la unidad, de lo absoluto, a la manera de Hegel o de las teorías materialistas? Para el último Merleau-Ponty ese ser unitario se llama "carne" (chair), es decir, unidad de lo existente a través de nuestra corporalidad sensible. En cuanto a la "reflexividad", el desdoblamiento (por ejemplo, vidente-visible) es la característica primordial de la carne, y el monismo inicial se transforma inmediatamente en un dualismo o, más bien, en un pluralismo. Lo sensible consiste de manera intrínseca en una pluralidad de modos de ser. Pero, ¿existe la sensibilidad independientemente del sujeto humano? Tal sería la pregunta que podría hacerse al filósofo francés desde la posición del realismo especulativo. Más aún: ¿su ontología de lo sensible es todavía fenomenología, es decir, descripción de un fenómeno dado a la conciencia humana? Algunos estudiosos de Merleau-Ponty, como Barbaras 1991, suponían que la ontología de nuestro filósofo es necesariamente fenomenológica, que es todavía una prolongación de la fenomenología. Mi observación crítica consiste en señalar que los conceptos novedosos que emplea Merleau-Ponty en Lo visible y lo invisible para caracterizar el mundo sensible - reflexividad, generalidad, ejemplaridad, sobreposición, compenentración, quiasmo, etc. - muestran la necesidad de un pensamiento especulativo, transempírico y transfenoménico, que funda justo el carácter estrictamente ontológico, ya no fenomenológico, de su perspectiva. Cierto, sólo podemos tomar conciencia de esa posibilidad implícita

10 "El propio cuerpo está en el mundo como el corazón en el organismo; mantiene continuamente en vida el espectáculo visible, lo anima y lo alimenta interiormente, forma con él un sistema" (Merleau-Ponty 1993, p. 219). 
en la filosofía de Merleau-Ponty si adoptamos hoy la perspectiva del nuevo realismo.

\section{2. "Campo fenomenal" y "campo de sentido". Merleau-Ponty y Markus Gabriel}

Frente a la oposición radical que Meillassoux restablece entre el "seren-sí", objeto de una ontología especulativa, y el "ser-para-mí" (o "para-nosotros") del pensamiento escéptico o subjetualista del correlacionismo, la filosofía de Merleau-Ponty, que no deja de constatar la paradójica condición de un "en sí" que es "para nosotros" (Merleau-Ponty 1993, p. 336), puede repensarse, de manera menos contrastante, si la relacionamos con el nuevo realismo de Markus Gabriel. En principio, Gabriel no establece una contraposición tan extrema entre el mundo sensible y el ámbito ontológico como la que traza Meillassoux. ${ }^{11}$ Según Gabriel, "estamos legitimados para someter a reflexión teórica y mantener incólume nuestra experiencia preontológica de una pluralidad de ámbitos de objetos. Esto se lleva a cabo en forma de un radical pluralismo ontológico" (Gabriel 2019b, p. 9). Gabriel aboga por una ontología pluralista o, en términos más precisos, por una ontología de los campos de sentido, y sostiene: "La forma lógica de esta ontología está anclada en nuestra experiencia preontológica, que ya en el plano de nuestra sensibilidad, es decir, en el plano de la percepción, nos confronta con un campo continuo de la realidad que internamente es casi infinito" (p. 10).

En sus últimos textos, Merleau-Ponty también abogaba por una ontología pluralista. ${ }^{12}$ Ciertamente, a diferencia del realismo especulativo

${ }^{11}$ En general, existen diferencias notables entre los proyectos filosóficos de ambos pensadores. Gabriel no acepta la crítica radical al correlacionismo que hace Meillassoux ni la vía especulativa que éste propone. Tampoco su afirmación del carácter absoluto de la contingencia. Por su parte, Meillassoux no ha escrito - hasta donde sé- alguna respuesta a las críticas de Gabriel. Véase Gabriel 2017, pp. 409 y ss. Por mi parte, sólo me interesa precisar que Meillassoux no se contenta con cuestionar o negar la correlación. Más bien, su estrategia teórica consiste en radicalizarla a través de una especie de metarreflexión que permita revelar su carácter contingente y, por ende, la propia contingencia de los términos correlacionados: el sujeto y el objeto, el pensamiento y el ser. En este sentido, el último Merleau-Ponty acepta, con la noción de "ser sensible" (carne), la contingencia de la correlación y de toda relación.

${ }^{12}$ Sobre el plan de Merleau-Ponty para desarrollar una ontología, "ontología del Ser bruto y del logos", que quedó sin realizar debido a su prematura muerte en 1961, véase Merleau-Ponty 1970, pp. 205-207. El "pluralismo ontológico" de 
de Meillassoux, él no se proponía —no quería- abandonar la primacía filosófica del campo fenomenológico-sensible del Ser. En todo caso, consideraba que el pensamiento y la vida general del espíritu —el lenguaje, el arte, la cultura, la ciencia, la vida social— era como una prolongación de las estructuras del mundo percibido: hablaba, por ejemplo, de una "percepción del pensamiento" (Merleau-Ponty 1964, pp. 193 y ss.) que, al igual que la percepción sensible, no domina su objeto, no lo tiene ante sí como un "objeto constituido", sino que sólo lo capta en la medida en que participa en él, sin poder presumir nunca una aprehensión total de la cosa - la cosa de la percepción o la cosa del pensamiento-. En otras partes habla de una percepción del lenguaje (Merleau-Ponty 1971), de una percepción estética (Merleau-Ponty 2013), de una percepción de lo social y hasta de una percepción de la historia. ${ }^{13}$

Por su parte, Gabriel sostiene que el pensamiento es un sentido más - una especie de sexto sentido o sentido común, a la manera de Aristóteles-, que nos permite aprehender lo real como tal. Al igual que Merleau-Ponty, Gabriel pretende "deshacer el error básico de la epistemología contemporánea: la dicotomía sujeto-objeto" (Gabriel 2019b, p. 33) o pensamiento-realidad.

Hay que tener en cuenta que, como seres pensantes y sensibles que somos no nos enfrentamos a una realidad aislada de nosotros mismos. El sujeto y el objeto no son partes opuestas de un todo de orden superior. Somos, más bien, parte de la realidad, y nuestros sentidos son medios que establecen contacto entre lo real, que somos nosotros mismos, y lo real, que no somos nosotros mismos. (p. 33)

Merleau-Ponty sostenía que no hay una realidad independientemente de la relación cuerpo-mundo, mientras que Gabriel sostiene que no hay una realidad, es decir, que no existe la totalidad de todo lo existente o, simplemente, que "el mundo no existe" (Gabriel 2016a). Por razones distintas a las de la fenomenología, razones lógicas más que

Merleau-Ponty se define en los términos siguientes: "lo que existe es toda una arquitectura, todo un escalonamiento de fenómenos, toda una serie de 'niveles de ser', que se diferencian por ese enrollarse de lo visible y lo universal en cierta realidad visible en la que se duplica y se inscribe" (Merleau-Ponty 1970, p. 145). Para un amplio estudio reciente sobre el pensamiento de Merleau-Ponty, véase Dalissier 2017.

${ }^{13}$ Sobre la extensión que hace Merleau-Ponty de su filosofía de la percepción a una filosofía general de las formas de expresión, véanse los artículos incluidos en Signos (Merleau-Ponty 1964) y su conferencia de ingreso a El Collège de France (Merleau-Ponty 2009). 
experienciales, lo que Gabriel niega no es la participación de una subjetividad en nuestra aprehensión del mundo, sino justo que haya un mundo, esto es, una totalidad completa y acabada. Insiste también en que el sujeto y el pensamiento son reales, que no se encuentran fuera de lo existente - "No hay visión de sobrevuelo", decía MerleauPonty-. ${ }^{14}$ En la medida en que el sujeto es real y que la totalidad no existe, lo que resta es una pluralidad indefinida de "campos de sentido". Es importante precisar que para Gabriel estos campos son estructuras ontológicas y no construcciones subjetivas —al igual que Meillassoux, el filósofo alemán combate las formas del constructivismo propias del pensamiento posmoderno-. De esta manera, Gabriel supera los escollos, por un lado, del pensamiento fenomenológico al suponer que existe la realidad en sí misma y que podemos conocerla y pensarla y, por otro lado, del reduccionismo fisicalista del cientificismo al sostener que esa realidad no constituye una totalidad ni tiene un modo único de existir: es plural; hay "infinitos campos de sentido" (Gabriel 2017, p. 305). Aunque Merleau-Ponty también rechazaba la idea de que las estructuras ontológicas de lo sensible fueran la construcción de una conciencia, sí consideraba que esas estructuras no existían sin la participación de un sujeto corporal, o bien, ya en la última etapa de su pensamiento —-más alejado de la fenomenología-, sin la referencia a una sensibilidad general (la chair), propiamente ontológica. Como he dicho, el pluralismo ontológico de Gabriel se prefigura también en la última obra de Merleau-Ponty (1970).

Sin embargo, debemos reparar en las diferencias entre las perspectivas de ambos filósofos en relación con el concepto de "campo perceptivo". Respecto al tratamiento de la percepción, Gabriel contrapone dos modelos teóricos: el que llama "modelo fenomenológico" y el que él defiende, "el modelo realista". Ahora bien, la descripción que ofrece del primero no corresponde en sentido estricto a toda la fenomenología como, por ejemplo, la de Merleau-Ponty — que es una fenomenología de la vida corporal y no de la conciencia-, sino a una concepción más bien husserliana o incluso propia del empirismo clásico inglés o de la antigua psicología reflexológica. Según Gabriel, para el modelo fenomenológico "la percepción de los objetos nos envía a las sombras o a los perfiles (Abschattungen) de las cosas mismas" (Gabriel 2018, p. 39); es decir, sólo percibimos "aspectos" de la cosa, pero no la cosa misma. De esta manera, ese modelo da lugar a posiciones escépticas respecto

\footnotetext{
${ }^{14}$ Expresión que emplea Merleau-Ponty en varios textos; por ejemplo, en Merleau-Ponty 1964, p. 225. Cfr. Bech 2005, p. 62 y ss.
} 
a la capacidad de nuestra percepción - y de todo conocimiento- para aprehender la realidad.

Sin embargo, la Fenomenología de la percepción contraviene todo el tiempo el "modelo fenomenológico" que caracteriza Gabriel. También para Merleau-Ponty percibimos las cosas mismas y no aspectos de ellas o, más bien -lo que sería la descripción correcta de nuestra experiencia-, percibimos la cosa misma a través de uno de sus aspectos o perfiles. Como afirma Claude Romano, si bien Merleau-Ponty rechaza el realismo explicativo (que las cosas causan la percepción que tenemos de ellas), sí adopta un realismo descriptivo: "la percepción no puede ser descrita de otro modo que como apertura al mundo mismo, en ausencia de todo intermediario mental" (Romano 2010, p. 571). Es la suposición de que nos representamos cualidades aisladas, sin ningún contexto y ubicación en el mundo, lo que da lugar al error de la explicación empirista de la percepción y a la insuficiente caracterización por parte de Gabriel del "modelo fenomenológico".

Retomaré aquí el ejemplo del cubo para explicar la idea de MerleauPonty del carácter realista de nuestra percepción (realismo descriptivo o perceptual). No debo decir que "percibo tres lados de un cubo", como si fueran tres extrañas superficies fantasmales que vuelan frente a mí; debo decir, como se sigue de las descripciones de Merleau-Ponty, que percibo un cubo en su totalidad a través de tres de sus lados (MerleauPonty 1993, p. 261). Y no es porque adivine o infiera el resto de los lados - la experiencia nos enseña a todos que no necesitamos añadir aquí ninguna operación mental: percibimos el cubo total de forma inmediata-. Sucede que la disposición de los tres lados captados, que depende de la perspectiva que tengo de ellos, ya nos dice que se trata de un objeto profundo, de seis lados. En términos geométricos, no veo en sentido estricto tres cuadrados: veo, sin que deba tener una conciencia teórica del asunto, tres trapecios de extensión desigual.

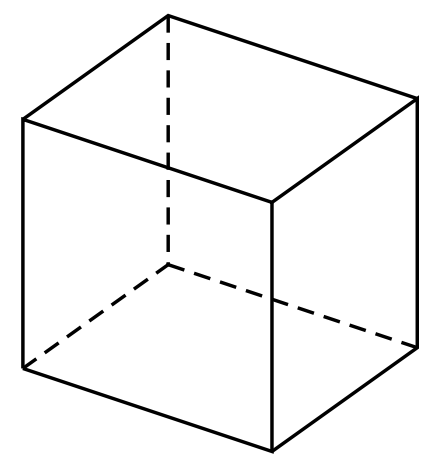

Diánoia, vol. 66, no. 86 (mayo-octubre de 2021) • elSSN 1870-4913 DOI: 10.22201/iifs.18704913e.2021.86.1778 
La posición y configuración de estos trapecios expresa la profundidad del objeto y la existencia y posición de los tres lados invisibles, de la misma forma en que la figura mayestática del Pantocrátor expresa ya su jerarquía espiritual absoluta. No hay que decir entonces que no percibo el cubo y que sólo capto, me represento, tres aspectos (lados) de él: hay que decir que percibo el cubo en cuanto tal a través de tres de sus lados. En los lados visibles están copresentes, co-implicados, los lados invisibles.

Para Merleau-Ponty, lo perceptible y lo imperceptible, lo visible y lo invisible, no son discontinuos, absolutos cada uno en su propia cualidad; no constituyen una dicotomía, sino una unidad compleja: lo visible es lo visible de lo invisible y lo invisible es lo invisible de lo visible. Hay concatenación entre ambos, no una separación como si fueran dos sustancias distintas o pertenecieran a mundos distintos (el mundo sensible y el mundo intelectual). Cada dimensión habla de la otra, la indica, la muestra, la expresa. El modelo de Merleau-Ponty es más bien un "modelo expresivista" y no uno fenomenológico (en los términos de Gabriel) o intelectualista o hermenéutico: tampoco hay que decir que nuestra percepción interpreta las tres caras visibles para inferir la existencia de las otras tres invisibles. Veo en la disposición de las visibles la existencia y la forma de las invisibles, como puedo ver en la mirada de alguien su inquietud, su alegría o su pesadumbre: su alma. No se trata aquí de una relación de significación; no es que lo visible signifique lo invisible. Lo visible expresa inmediatamente lo invisible, la mirada de alguien expresa de forma directa su alma; no son dos cosas separadas y sólo relacionadas de manera externa, se comunican interiormente y en todo momento.

El aspecto perceptivo del cenicero [o del cubo] no es al "cenicero mismo" lo que un acaecer es a otro que anuncia, o lo que un signo es a lo que significa. Ni la consecución de los "estados de conciencia" ni la organización lógica del pensamiento dan cuenta de la percepción: la primera porque es relación exterior, en tanto que los aspectos perspectivos del cenicero son representativos los unos de los otros; la segunda porque supone un espíritu en posesión de su objeto, en tanto que mi voluntad carece de acción directa sobre el desarrollo de las perspectivas percibidas y que su multiplicidad concordante se organiza por sí misma. (Merleau-Ponty 1993, p. 261)

El modelo fenomenológico que construye Gabriel es, pues, inexacto, al menos en lo que respecta a la fenomenología de Merleau-Ponty. Esto tiene consecuencias importantes. Mientras que para Gabriel, como ya 
indiqué, aunque el pensamiento se sustenta en la experiencia sensible existe de todas formas una discontinuidad entre ambos niveles, para Merleau-Ponty el pensamiento es prolongación de la experiencia perceptiva, es su expresión. El pensamiento es el sentido sinestésico, el "sexto sentido", la "síntesis intersensorial" que nos permite captar la realidad en su concreción y verdad (Merleau-Ponty 1993, pp. 240 y ss.). La perspectiva de Merleau-Ponty es realista, y la diferencia entre el modelo de éste, "expresivista", ${ }^{15}$ y el "modelo neorrealista" de Gabriel, debe ser otra.

Merleau-Ponty describe el campo fenomenal como el entorno de una subjetividad corporal, que es como el punto cero de ese campo y define sus articulaciones, sus distancias y relaciones, y que deja incluso lugares ocultos o difusos, que son los espacios donde otras subjetividades pueden aparecer: hay cosas que no veo, pero cuento con que otros videntes pueden verlas o que las están viendo; lo que veo no es sólo mío, sino también del otro, de los otros, y por eso existe. Gabriel, desde una postura plenamente realista, define la diversidad de perspectivas como elementos de lo real: no sólo son reales el sujeto y el objeto y los otros sujetos. Para Gabriel, el "campo perceptivo" consta en realidad de tres elementos o componentes, todos reales por igual: el sujeto, el objeto percibido y el medio o contexto real, y no sólo fenoménico, donde la percepción acontece.

Mientras que para Merleau-Ponty el contexto de lo percibido sólo tiene una realidad fenomenológica (en el nivel del aparecer), para Gabriel tiene, además, una realidad objetiva, incluso material-energética. El modelo neorrealista, nos dice, "piensa el sol desde el punto de vista de la física, como un campo electromagnético, por ejemplo. El sol sólo puede afectar nuestros sensores (nuestra piel, nuestras terminales nerviosas, etc.) porque este campo se extiende hasta nosotros. Lo acogemos como si fuera la luz del día" (Gabriel 2018, p. 43). Esta-

${ }^{15} \mathrm{El}$ expresivismo - la idea de que hay relaciones expresivas entre las cosas o entre las cualidades de las cosas, más allá incluso de que haya o no un sujeto-, tiene un lugar un poco perdido en la historia de la filosofía. Se ha defendido en la estética, pues resulta el mejor modelo para pensar las relaciones entre los distintos aspectos o elementos de una obra de arte. Fuera de este campo, el expresivismo está presente todavía en las filosofías inmanentistas de Bruno, Spinoza y Leibniz (Deleuze 1975, cap. XI, "La inmanencia y los elementos históricos de la expresión", pp. 164-180), en la "episteme" renacentista (Foucault 1968, cap. II, "La prosa del mundo", pp. 26-52), en la tradición hermética y en el pensamiento mítico-mágico estudiado por los antropólogos. El expresivismo se vincula con una visión holística de lo real, que muestra, según la ontología de Merleau-Ponty, la unidad general de lo subjetivo y lo objetivo, de lo espiritual y lo material. 
mos dentro del campo del sol, lo percibimos como desde su interior: nuestra percepción del sol es como la percepción del sol mismo. En un texto reciente, Gabriel afirma que al ver una estrella en la lejanía debemos admitir "que somos una parte del campo de la estrella". ${ }^{16} \mathrm{El}$ "campo perceptivo" de Merleau-Ponty — con sus luces y sombras, su peso o su ligereza, sus ruidos o silencios- es posible a partir de ese "campo energético-objetivo" descrito por Gabriel. Aunque, ciertamente, somos parte de este campo, no se define, de ninguna manera, a partir de nosotros, como sí sucede con el campo fenomenal de Merleau-Ponty. Esta aportación de Gabriel abona de manera efectiva al reconocimiento de la capacidad de nuestra percepción para aprehender lo real en sí mismo. Hay que decir que no sólo percibimos el sol, sino que el sol se percibe a sí mismo a través de ese campo, y que, de alguna manera, nosotros somos el sol que se percibe a sí mismo. Merleau-Ponty decía lo mismo: "no somos nosotros quienes percibimos, es la cosa la que se percibe ahí" (Merleau-Ponty 1970, p. 228). Lo que él quería mostrar, que hay unidad plena entre el sujeto perceptivo y el mundo percibido (la chair, la "carne"), lo justifica Gabriel de manera plena, ciertamente desde una perspectiva ya no fenomenológica, sino objetiva o, más bien, ontológica. Accedemos a la realidad porque somos parte de ella, y por esta misma razón - porque el sujeto está hundido en el mundo- no hay una realidad única y total, sino múltiples campos de sentido, múltiples modos en que lo real acontece. Gabriel da el paso definitivo hacia la ontología, esto es, hacia la afirmación de la existencia indubitable de lo real, donde está incluido el propio sujeto, y para hacerlo no ha tenido que romper de forma total con la experiencia, sino entender lo que ella enseña: que la realidad existe, y que hay que pensar desde esta constatación. El pensamiento no sólo nos permite aprehender el ser entero de la cosa, sino además definir positivamente su realidad. Merleau-Ponty acepta esta realidad, pero al tener como criterio único a la percepción sólo puede definirla en términos negativos: como una subsistencia que persiste "más allá" y nos resiste (Merleau-Ponty 1993, pp. 336-338). Para Gabriel, el pensamiento puede sostener que el objeto existe por sí mismo, algo que la percepción no alcanza a hacer. En cuanto que es un sentido, el pensamiento se remite a algo exterior, pero en la medida en que es más que un sentido sensible su operación puede referirse a la cosa en cuanto tal, independientemente de mi pura subjetividad. La cosa no está dentro de mi conciencia ni es el puro correlato de ella, no es objeto-para-la conciencia.

16 "Nous sommes une partie du champ de l'étoile" (Gabriel 2020, p. 203). 
No obstante, es en su refutación del reduccionismo neurológico —que él llama neurocentrismo- donde Gabriel expone sus ideas más claras tanto respecto a la aportación de la fenomenología como respecto a su límite ontológico y epistemológico. En Yo no soy mi cerebro propone distinguir entre dos formas de conciencia: la conciencia intencional y la conciencia fenoménica. "La conciencia intencional", señala, "es nuestra referencia a otra cosa, y está dotada de una perspectiva hacia el exterior, una percepción externa" (Gabriel 2016b, p. 111). El autor retoma el concepto de "intencionalidad" de Husserl y de la fenomenología, pero le da un giro realista. Mientras que para el fundador de la filosofía fenomenológica el "objeto intencional" (o "intencionado") es un correlato de la conciencia, para Gabriel el objeto intencional rebasa a la conciencia: ésta "accede" a algo distinto de ella; la conciencia "tiene un acceso atento a estados de información", es decir, a lo que llamamos propiamente conocimiento. Por su parte, la conciencia fenoménica "está relacionada con nuestra perspectiva interna", puramente subjetiva; su contenido "son los [...] qualia o sensaciones" (p. 111); esto es, las cualidades sensibles: colores, olores, sonidos, sabores, texturas, formas, paisajes, etc., y, en general, el mundo fenoménico-vivencial que existe tanto como el mundo puramente físico-objetivo.

La distinción entre la conciencia intencional y la conciencia fenoménica le sirve a Gabriel para criticar la reducción materialista-naturalista de la mente (del Yo) al cerebro. Así, cuestiona primero la identificación de la mente con un ordenador o computadora (IA) y responde de manera negativa a la pregunta de si los robots pueden tener conciencia. Sólo podríamos suponer "realmente conscientes a los robots humanoides si dispusiéramos exclusivamente de conciencia intencional, pero no de conciencia fenoménica" (pp. 114-115). En otras palabras, la conciencia intencional, esto es, la conciencia objetiva, puede ser reproducida por la inteligencia artificial, o ésta puede hacerse un modelo de aquella, pero es imposible que un robot reproduzca o imite la conciencia fenoménica, la conciencia de ser un sujeto - la conciencia propiamente-, por más humano que parezca. "El robot no tiene conciencia fenoménica; no tiene experiencia, no tiene ganas de nada" (p. 115).

Un robot no puede tener conciencia fenoménica y, por la misma razón - porque no es una realidad analítica, cuantificable-, ésta tampoco es ubicable en el cerebro, en nuestra realidad físico-biológica; es algo propiamente humano y lo humano consiste en la posesión de esa conciencia. Ciertamente, tal forma de conciencia es correlacionalista, conlleva necesariamente ser un punto de vista o una perspectiva so- 
bre lo exterior y articular un campo fenomenológico a su alrededor (el "ser-en-el-mundo" de Heidegger). La conciencia fenoménica está ligada a nuestra condición material, corporal e incluso evolutiva, aunque no se puede reducir de ninguna manera a esa condición; ella configura un modo de ser por entero original y, para Merleau-Ponty, originario: es la base primera de nuestro ser, del conocimiento y de la vida humana, individual y colectiva. La conciencia fenoménica es, como bien lo calibró Merleau-Ponty en toda su complejidad y profundidad, la verdad fundante de nuestra conciencia. Para él, y a diferencia de Gabriel que permanece en cierto dualismo respecto a la conciencia (intencional y fenoménica), hay un movimiento unitario entre ambas formas de conciencia; no hay discontinuidad o ruptura: la conciencia fenoménica tiene un carácter relacional, nos conecta con algo fuera de nosotros, y la conciencia intencional tiene una base primera en nuestra percepción, la cual, como reconoce el propio Gabriel $2020,{ }^{17}$ conlleva pensamiento, "conceptos" no lingüísticos (Romano 2010) ${ }^{18}$ En el siguiente apartado precisaré este detalle, que tiene que ver, en última instancia, con la relación entre el mundo fenoménico y el mundo objetivo, es decir, entre la conciencia y lo real que existe con independencia de ella.

\section{Contacto ontológico}

La conciencia fenoménica no es, pues, toda la conciencia humana. Existe un estrato de la conciencia, el intencional, que tiene que ver con la capacidad de nuestro pensamiento para acceder a lo real como tal. La diferencia entre Gabriel y Merleau-Ponty estriba en que para el primero (y para Meillassoux 2015) no existe una relación de condicionamiento entre la conciencia fenoménica y la conciencia intencional: son simplemente dos niveles o instancias independientes. Ahora bien, aunque no se sostenga una relación de dependencia entre ambas conciencias - de la conciencia intencional a la fenoménica o al revés- no podemos dejar de pensar la relación entre ellas. Tal es la asignatura pendiente que los nuevos realismos, de Meillassoux, Gabriel y otros (Ray Brassier, Graham Harman, Tom Sparrow, etc.) no deberían ignorar si quieren proponer un realismo integral, que piense la realidad de las cosas y también la realidad de nuestra conciencia.

Con el propósito de recuperar el realismo, Charles Taylor y Hubert Dreyfus han defendido recientemente la postura de Merleau-Ponty, para

${ }^{17}$ Cfr. cap. 6, "Les couches de la perception", pp. 189-207.

${ }^{18}$ Cfr. cap. IX, "Le concept de concept", pp. 328 y ss.

Diánoia, vol. 66, no. 86 (mayo-octubre de 2021) • elSSN 1870-4913

DOI: 10.22201/iifs.18704913e.2021.86.1778 
quien la conciencia fenoménica o conciencia perceptiva - la "teoría del contacto" la llaman ellos (Dreyfus y Taylor 2016, p. 42)— constituye la primera y más contundente forma de realismo, en la cual han de fundarse las demás. En particular, las "teorías del contacto pre-conceptual" son la mejor vía para refutar y superar el subjetivismo idealista del pensamiento moderno - propósito también del nuevo realismo- que Dreyfus y Taylor llaman, por su parte, la "teoría mediacional". Mientras que ésta "hace depender el saber de un elemento de mediación, de modo que este factor intermedio, ya sean categorías o representaciones, posibilite el contacto con lo real, para las teorías del contacto el saber depende de un contacto no mediado con la realidad que pretendemos conocer" (pp. 42-43). De esta manera, dicen, "el verdadero conocimiento es una especie de contacto no mediado" (p. 43); el modo "vinculado" de la relación del sujeto corporal con el mundo concreto "precede al desvinculado" (p. 72). Frente a la relación de separación y mediación tenemos el "afrontamiento incrustado" (p. 178) o, como decía Merleau-Ponty, la inherencia, la encarnación, la superposición, el quiasmo sujeto-mundo, etc., que se expresa en la forma de una comprensión prelingüística y no conceptual o, como la llama la hermenéutica, una "pre-comprensión".

No obstante, Dreyfus y Taylor no se conforman con la idea de que la conciencia objetiva - el saber científico, propiamente- es sólo una extensión de la conciencia corporal, pues esto implicaría cuestionar la validez objetiva del conocimiento científico, algo que para ellos es difícil de aceptar aunque, a la vez, rechazan la postura meramente cientificista. Así, podemos interpretar que Taylor y Dreyfus se oponen tanto a la posición de Merleau-Ponty — prioridad de la conciencia corporal sobre la conciencia objetiva - como a la de Gabriel —independencia y autonomía de la conciencia objetiva respecto a la conciencia corporal (o fenoménica). Se trata, pues, de encontrar una tercera posición, una posición intermedia entre las dos mencionadas. ¿Cuál podría ser? Es aquí que nuestros autores retoman la filosofía de Samuel Todes y la evaluación que de ella hace Piotr Hoffman (Dreyfus y Taylor 2016, p. 223), en el sentido de lo que podemos llamar una fenomenología del cuerpo como "sujeto material del mundo" (Todes 2001, p. 1), o una ontología de la corporalidad. Según Todes, hay una estructura básica de nuestra realidad corporal, una dimensión propiamente ontológica (universal) que determina tanto las posibilidades como los límites de nuestra aprehensión del mundo y de nuestra acción en él. Entre el campo horizontal —que determinamos nosotros como sujetos perceptores- y el campo vertical —que nos determina a nosotros como entes materia- 
les sometidos a la gravitación- debemos encontrar el equilibrio (Todes 2001, p. 122). En general, debemos encontrar el equilibrio entre una fenomenología subjetiva y una fenomenología material, entre la fenomenología y la ontología. "El equilibrio no es ni puramente activo, como sería moverse, ni puramente pasivo, como sería ser movido" (Dreyfus y Taylor 2016, p. 223). Ni nos movemos ni nada nos mueve; estamos en posición, podemos y debemos encontrar el punto intermedio, el equilibrio entre determinar los objetos o aceptar su determinación, y "sólo podemos determinarlos si nos hallamos ante una realidad que es verdaderamente independiente" (p. 225).

Por ejemplo, cojo el libro y busco la página donde está la cita anterior. No podría hacerlo sin considerar que el libro es un objeto que existe independientemente de mi aprehensión y, más aún, de mis deseos; que sin duda se me "ofrece" para que yo haga las operaciones requeridas - no es como una idea que puedo determinar a mi gusto ni un espectro o un "genio maligno" cuyas reacciones pueden resultar inesperadas o incomprensibles-. Sé más o menos qué puedo esperar, pero sé también que no lo determino todo, que los objetos poseen otras características que desconozco y que estas características me muestran al fin que los objetos poseen "una estructura que subyace a todo lo que permiten o hacen posible" (p. 225), y tal estructura existe por sí misma y no en función de mi aprehensión o de mis necesidades. Nuestra experiencia puede describirse de muchas maneras, pero es posible describir la estructura subyacente de las cosas de modos más o menos acertados y objetivos. La ciencia preserva para sí su carácter de conocimiento objetivamente válido. De la misma manera que nuestra percepción y praxis corporal nos acerca a objetos que no existen sólo en nuestra mente, nuestras prácticas científicas nos revelan una realidad que existe independientemente de esas prácticas. Según Dreyfus y Taylor, un realismo recuperado es un realismo plural. No sólo lo real es plural, como sostiene Gabriel, sino que hay una pluralidad de realismos -el realismo perceptual, el realismo científico, el realismo de tal o cual cultura, y podríamos agregar: el realismo artístico, el realismo político, el realismo ético, los realismos filosóficos, antiguos y nuevos (Benoist 2018), etcétera-. Ninguno tiene asegurada a priori su validez o su superioridad sobre los demás, pero es posible - y en esto consiste la filosofía - la discusión entre ellos y el logro de algunos acuerdos básicos.

Así, el reconocimiento del carácter material del sujeto corporal —la tesis de Todes- se presenta como la vía para una superación de la fenomenología de la conciencia, el propósito del último Merleau-Ponty, 
que pueda mantener el reconocimiento del valor y la función de la subjetividad corporal sin que esto implique convertir lo existente en mero "objeto" de y para ese sujeto y convalidar el antirrealismo. La realidad material de nuestro propio cuerpo es la evidencia primera (una evidencia siempre ya presupuesta) de que existe una realidad antes e independientemente de nuestra conciencia. ${ }^{19}$ Es el argumento primero contra toda postura idealista.

\section{Conclusión. Hacia un realismo ontológico}

He querido mostrar la pertinencia del pensamiento de Merleau-Ponty para la discusión filosófica actual, en particular en relación con las tesis del nuevo realismo y del realismo especulativo. El filósofo francés cuestionó un tipo de realismo - el realismo objetivista del pensamiento científico-, pero justo con el propósito de defender el realismo de nuestra percepción (lo que Romano llama "realismo descriptivo") y, de ahí, a la filosofía como un pensamiento capaz de hablar de lo real, o al menos de plantearse el problema de lo real, sin tener que dejar esta cuestión a cargo nada más de la ciencia. En la medida en que las ciencias nunca se desprenden por completo de la forma de nuestra relación perceptiva y existencial con el mundo, sino que son como una especie de sublimación de ella, ${ }^{20}$ Merleau-Ponty no se opondría al realismo científico ni a la afirmación de una realidad objetiva. Más bien sostendría que ese realismo científico, debido a que se basa en el realismo de nuestra percepción, no puede anular a ésta. Está claro que, si alguien nos ha enseñado que la realidad no nos es ajena ni inaccesible y que, por el contrario, somos esencialmente parte de ella, es precisamente el filósofo francés. Es verdad que el realismo especulativo de Meillassoux, el nuevo realismo de Gabriel o el realismo plural de Dreyfus y Taylor significan un punto de inflexión en la historia de la filosofía en la medida en que adoptan la postura realista en todo su significado y alcance. Pero también es cierto

${ }^{19}$ Una implicación de la definición de correlacionismo de Meillassoux, y que en general se pasa por alto, es que la superación crítica del correlacionismo debe ser capaz de pensar un objeto independiente del sujeto tanto como un sujeto independiente del objeto. La esfera de esta subjetividad ontológicamente autónoma es algo que no han analizado lo suficiente los nuevos realismos. El filósofo neorrealista Steven Shaviro, inspirado en el pensamiento de Graham Harman (otra de las figuras del nuevo realismo), aborda el asunto con el concepto de "pensamiento no correlacional". Cfr. Shaviro 2014, pp. 108 y ss.

20 "La vida humana se define por este poder que tiene de negarse en el pensamiento objetivo, y este poder le viene de su apego primordial al mismo mundo" (Merleau-Ponty 1993, p. 340). 
que el pensamiento de Merleau-Ponty no acertaba a definir una forma de realismo que le pareciera válida, aunque su indagación filosófica, atenta y siempre abierta, contribuyó, incluso de manera virtual, a señalar hacia esa forma, esto es, a vislumbrar un realismo que comprendiera toda realidad, sin mecanicismos ni ficciones ni mistificaciones; justo en el sentido en el que siempre se ha hablado, en filosofía y a veces en contra de ella, de ser realistas.

En todo caso, lo que sostengo aquí es que tanto el realismo de nuestra percepción como el realismo científico deben de superarse pero no negarse, sino más bien comprenderse a través de un realismo ontológico. Entiendo por éste el reconocimiento de que tanto la percepción como la ciencia suponen y dan cuenta a la vez de la existencia de una realidad independiente de nosotros pero que, sin duda, y como sostiene el nuevo realismo, sólo puede afirmarse de modo contundente en el acto del pensamiento - un pensamiento que acompaña a la percepción $\mathrm{y}$ a la ciencia pero que necesariamente tiene que trascender a ambas para poder explicarlas y comprenderlas-. Ese acto del pensamiento es, precisamente, el ámbito propio de la filosofía, esto es, del pensamiento especulativo. Así, el realismo ontológico consiste en la afirmación especulativa - esto es, racional, conceptual- de que, en efecto, la percepción y el conocimiento científico se refieren a una realidad que está más allá de nosotros. Afirma, pues, que no sólo existe este lado, sino también el otro lado y que ese otro lado debe pensarse necesariamente para que la percepción, la conciencia y la ciencia tengan un sentido y una verdad. La afirmación de la existencia, esto es, del carácter real de ambos lados y de la interrelación —no correlación-que existe entre ambos es la tesis del realismo ontológico que sostengo.

El realismo ontológico se distingue del realismo metafísico de la tradición filosófica en que no otorga un carácter sustancial, unitario, total y necesario a lo real. Acepta algunas partes de las afirmaciones de los autores analizados: que el sujeto, como sujeto corporal y sensible, es parte de lo real y que la percepción nos da acceso a lo que existe (Merleau-Ponty); que lo real no es una totalidad acabada, esto es, que no existe el todo de lo existente (el "mundo", según Gabriel) y que, por ende, como sostiene Meillassoux, la existencia es esencialmente contingente, ${ }^{21}$ no sólo es contingente la existencia humana, como suponía

${ }^{21}$ Ninguno de estos autores reconoce la relación intrínseca entre la tesis de la inexistencia del mundo de Gabriel y la contingencia de todo lo existente de Meillassoux, aunque a mí me parece que éste es el punto en que ambos filósofos se encuentran a pesar de sus reconocidas diferencias. La idea del carácter no totalizable de lo existente, esto es, de que "el mundo no existe", la planteó primero 
Merleau-Ponty, sino que lo es toda existencia. La incompletud, pluralidad, relatividad y contingencia que caracterizan a nuestra relación con lo existente son en verdad caracteres de lo propio existente. El equívoco consiste en suponer, en la inmediatez irreflexiva, que más allá de nuestra percepción y de nuestras ciencias resplandece un Ser puro, uniforme, necesario, estático. Esto no es más que una ficción, y es contra esta ficción dogmática e irreflexiva, es decir, contra la metafísica y la forma ideológica de pensar contra lo que va, en última instancia, toda postura realista. Así, el realismo ontológico se presenta como una especie de realismo transversal con respecto a las diversas posturas filosóficas que he citado porque todas ellas obedecen al intento de mantener la autonomía del pensar filosófico y su valor y función para la comprensión de lo real en cuanto tal.

\section{Referencias bibliográficas}

Barbaras, Renaud, 1991, De l'être du phénomène. Sur l'ontologie de MerleauPonty, Millon, Grenoble.

Bech, Josep Maria, 2005, Merleau-Ponty. Una aproximación a su pensamiento, Anthropos, Barcelona.

Benoist, Jocelyn (comp.), 2018, Réalismes anciens et nouveaux, Vrin, París.

Booth, Robert, 2018, "Merleau-Ponty, Correlationism, and Alterity", PhænEx. Revue de théorie et culture existentialistes et phénoménologiques, vol. 12, no. 2, pp. 37-58.

Dalissier, Michel, 2017, La Métaphysique chez Merleau-Ponty, 2 vols., Lovaina, Peeters.

Deleuze, Gilles, 1975, Spinoza y el problema de la expresión, trad. H. Vogel, Muchnik, Barcelona.

Dreyfus, Hubert y Charles Taylor, 2016, Recuperar el realismo, trad. J. Carabante, Rialp, Madrid.

Ferraris, Maurizio, 2013, Manifiesto del nuevo realismo, trad. J. Blanco Jiménez y otros, Biblioteca Nueva, Madrid.

Foucault, Michel, 1968, Las palabras y las cosas, trad. T. Segovia, Siglo XXI, México.

Gabriel, Markus, 2016a, Por qué no existe el mundo, trad. Enrique G. de la G., Océano, México.

Gabriel, Markus, 2016b, Yo no soy mi cerebro. Filosofía de la mente para el siglo XXI, trad. J. Madariaga, Pasado y Presente, Barcelona.

Gabriel, Markus, 2017, Sentido y existencia. Una ontología realista, trad. R. Gabás, Herder, Barcelona.

Gabriel, Markus, 2018, Le Pouvoir de l'art, Saint-Simon, París.

Meillassoux 1997 (cap. 4, "Infini cantorien et inexistence du Tout", pp. 17-23), aunque Gabriel ha obviado hacer este reconocimiento. 
Gabriel, Markus, 2019a, Neoexistencialismo. Concebir la mente humana tras el fracaso del naturalismo, trad. M. Figueras, Pasado y Presente, Barcelona.

Gabriel, Markus, 2019b, El sentido del pensamiento, trad. N. Fominaya, Pasado y Presente, Barcelona.

Gabriel, Markus, 2020, Propos réalistes, J. Vrin, París.

Heidegger, Martin, 2003, Aportes a la filosofía. Acerca del evento, trad. D.V. Picotti, Biblos/Almagesto, Buenos Aires.

Husserl, Edmund, 1949, Ideas relativas a una fenomenología pura y una filosofía fenomenológica, trad. J. Gaos, Fondo de Cultura Económica, México.

Meillassoux, Quentin, 1997, LInexistence divine, Universidad de París (accesible por scribd).

Meillassoux, Quentin, 2015, Después de la finitud. Ensayo sobre la necesidad de la contingencia, trad. M. Martínez, Caja Negra, Buenos Aires.

Meillassoux, Quentin, 2016, "Duelo por venir, Dios por venir", trad. M.T. Ramírez, en Ramírez 2016, pp. 101-111.

Merleau-Ponty, Maurice, 1957, La estructura del comportamiento, trad. E. Alonso, Hachette, Buenos Aires.

Merleau-Ponty, Maurice, 1964, Signos, trad. C. Martínez y G. Oliver, SeixBarral, Barcelona.

Merleau-Ponty, Maurice, 1970, Lo visible y lo invisible, trad. J. Escudé, SeixBarral, Barcelona.

Merleau-Ponty, Maurice, 1971, La prosa del mundo, trad. F. Pérez Gutiérrez, Taurus, Madrid.

Merleau-Ponty, Maurice, 1972, "Prefacio" a A. Hesnard, La obra de Freud, trad. M. Noriega Ezcurdia, Fondo de Cultura Económica, México.

Merleau-Ponty, Maurice, 1974, Las aventuras de la dialéctica, trad. L. Rozitchner, La Pléyade, Buenos Aires.

Merleau-Ponty, Maurice, 1993, Fenomenología de la percepción, trad. J. Cabanes, Planeta-Agostini, México.

Merleau-Ponty, Maurice, 2009, Elogio y posibilidad de la filosofía, trad. E. Bello Reguera, Universidad de Almería, Almería.

Merleau-Ponty, Maurice, 2013, El ojo y el espíritu, trad. A. del Río Hermann, Trotta, Madrid.

Ramírez, Mario Teodoro, 2013, La filosofía del quiasmo. Introducción al pensamiento de Merleau-Ponty, Fondo de Cultura Económica, México.

Ramírez, Mario Teodoro, 2016, El nuevo realismo. La filosofía del siglo XXI, Siglo XXI, México.

Romano, Claude, 2010, Au Coeur de la raison, la phénoménologie, Gallimard, París.

Shavirto, Steve, 2014, The Universe of Things. On Speculative Realism, The University of Minnesota Press, Mineápolis.

Sparrow, Tom, 2014, The End of Phenomenology. Metaphysics and the New Realism, Edinburgh University Press, Edimburgo.

Taylor, Charles, 2019, "La refutación de Gabriel”, en Gabriel 2019a, pp. 81-92.

Diánoia, vol. 66, no. 86 (mayo-octubre de 2021) • elSSN 1870-4913

DOI: 10.22201/iifs.18704913e.2021.86.1778 
Toadvine, Ted, 2014, "The Elemental Past", Research in Phenomenology, vol. 44, no. 2, pp. 262-279. <DOI: 10.1163/15691640-12341288>.

Todes, Samuel, 2001, Body and World, MIT Press, Cambridge.

Vrahimis, Andreas, 2013, "Was There a Sun Before Men Existed?: Ayer, Sartre, Bataille, and Merleau-Ponty", en A. Vrahimis, Encounters Between Analytic and Continental Philosophy. Language, Discourse, Society, Palgrave, Macmillan, Londres.

Waelhens, Alphonse de, 1978, Une Philosophie de la ambiguïté. L'existentialisme de Maurice Merleau-Ponty, Nauwelaerts, Lovaina.

Zahavi, Dan, 2016, "The End of What? Phenomenology and Speculative Realism", International Journal of Philosophical Studies, vol. 24, no. 3, pp. 289309. <https://doi.org/10.1080/09672559.2016.1175101>.

Recibido el 5 de abril de 2020; revisado el 12 de septiembre de 2020; aprobado el 26 de octubre de 2020. 